\title{
The Effect of Naloxone on Pentazocine Induced Hallucinations
}

\author{
Maj $R \mathrm{H}$ Jago \\ MA, FFARCS, RAMC \\ Lt Col J. Restall \\ MB BS, FFARCS, RAMC \\ Capt J Stonham \\ MB BS, FFARCS, RAMC \\ Department of Anaesthesia \\ Cambridge Military Hospital, Aldershot
}

\section{A Case Report}

SUMMARY: A case of pentazocine induced hallucinations which responded to treatment with Naloxone reported.

\section{Introduction}

Orr and Oppenheimer ${ }^{1}$ and Gunne, Lundstrom and Terenius $^{2}$, have shown that auditory hallucinations can be abolished in schizophrenic patients by the administration of Naloxone (n-allyl-nor-oxy-morphone), a pure narcotic antagonist. Maugh $^{3}$ has also reported that it abolishes the hallucinations produced by narcotic analgesics. The use of Naloxone to treat pentazocine induced hallucinations is detailed.

\section{Case History}

A 17 year old male was admitted with a fractured femur following a road traffic accident. It was decided to treat the broken bone by means of internal fixation with a Küntscher nail. He was a fit youth weighting $78 \mathrm{~kg}$, with no past history of serious illness or psychiatric instability. He had not received any drug therapy in the previous six months, but had been started on ampicillin $250 \mathrm{mg}$ /fiucloxacillin $250 \mathrm{mg}$ (Magnapen) intra-muscularly four times a day on admission.

Routine pre-operative preparation was instituted and the patient premedicated with pentazocine 60 $\mathrm{mg}$ and atropine $0.6 \mathrm{mg}$ intramuscularly one hour before surgery. Anaesthesia was induced intravenously with thiopentone $400 \mathrm{mg}$ and pancuronium 8 mg. The patient was intubated and ventilated with nitrous oxide, $30 \%$ oxygen, and halothane. Surgery was completed in 45 minutes, paralysis reversed with neostigmine $2.5 \mathrm{mg}$ and atropine $1.2 \mathrm{mg}$, and the patient returned to the recovery ward. Pentazocine $60 \mathrm{mg}$ intramuscularly was prescribed for pain relief.
About 45 minutes after receiving his first postoperative dose of pentazocine the patient was noticed $\mathbb{\Phi}$ to be behaving in a most bizarre manner. He was thrashing about in the bed, gasping for air, and sweating. Although rousable he was incoherent, and the nursing staff were unable to pacify him. One of the authors (JS) was called, and following rapide assessment of the situation gave Naloxone $0.4 \mathrm{mg}$ ? intravenously.

Within two minutes the patient had calmed down and was rational. He said that he had been having a strange and frightening dream, but was unable to recount exact details of its content. Aware of the short duration of action of Naloxone, and consequently fearful of a return of symptoms, a further $0.4 \mathrm{mg}$ was given intramuscularly. The patient was closely observed overnight, but suffered no further disturbance. Subsequent an lgesia was provided by means of a femoral nerve block.

\section{Discussion}

Pentazocine is known to be associated with psychotomimetic side effects, the commonest of which are hallucinations $s^{4}$. This patient clearly suffered a severe disturbance, the most likely precipitating agent being the pentazocine used for post-operative analgesia. The rapid return of normal behaviour following intravenous Naloxone underlines the speed of action of this drug.

It has been suggested that the hallucinations associated with schizophrenia are caused by the interaction of excess naturally occurring endorphins and 
brain opiate receptors ${ }^{2}$. The mechanism involved in producing pentazocine induced psychotomimetic reactions is as yet unknown. Holtzman and Jewett ${ }^{5}$ reported a rapid fall in brain nor-adrenaline and dopamine levels following the administration of pentazocine, with no alteration in the turnover rates of neuro-transmitters. Similar rapid release of brain amines is seen with amphetamine therapy. Byrd and $\mathrm{Kane}^{6}$ suggested that pentazocine may interact with an underlying personality disorder or with preexisting sub-clinical neuronal damage.

That narcotic antagonists block the euphoric effects of opiates has long intrigued investigators in the field of heroin addiction ${ }^{3}$. This case report confirms their observations, and may have important implications for the role of endorphins and opiate receptors in the pathogenesis of pentazocine induced hallucinations.

\section{REFERENCES}

1 ORR M AND OPPENHEIMER C. Effects of naloxone or auditory hallucinations. $\operatorname{Br} \operatorname{Med} J$ 1978; 1: 481. 응

2 Gunne $L$ M, Lundstron $L$ and Terenius $L$ Naloxone induced reversal of schizophrenic halluO cinations. J Neural Transm 1977; 40: 13-19.

3 Maugh $T$ H. Narcotic antagonists: the search: accelerates. Science 1972; 177: 249-250.

4 Coursey C E. The psychotomimetic side effects of pentazocine. Drug Intelligence and Clin Pharmacot 1978; 12: 341-346.

5 Holtzman S C and Jewett R E. Some actions of pentazocine on behaviour and brain monoamine in the rat. J Pharmacol Exp Ther 1972; 181: 346-356

6 Byrd G J and Kane F J. Persistent psychotic phenomena following one dose of pentazocine. Tex Meb 1976; 72: 68-69.

The following is a list of officers of the US Army Medical Corps who have served as Medical Liaison Officers to DGAMS. The Editor would be grateful for the name of the officer who served from 1947 to 1949.

Maj Arthur B Welsch MC

Col Paul R Hawley MC

May-Sep 1941

LTC Tom F Whayne MC

Sep 1941-43

1943-44

Maj Sarah Bowditch MC

1944-45

LTC David Greeley MC

1946-47

$1947-49$

LTC John Reagan MC

$1949-52$

Col Walter $\mathbf{H}$ Moursund $\mathrm{MC}$

1953-55

Col Conn L Milburn MC

Col John C Cressler MC

Col John Voegtley MC

Col Adolphe J Schoepflin MC

Col Harry W McCurdy MC

Col Michael M Duffy MC

Col. Thomas L Lamson MC 